\title{
Análise da Situação de Trabalho de Motoristas em uma Empresa de Ônibus Urbano da Cidade de Natal/RN
}

Analysis of the Drivers' Work Situation of an Urban Bus Company in Natal/RN

Análisis de la Situación de Trabajo del Conductores de Autobús Urbano en una Empresa en la Ciudad de Natal/RN

Ladijane Sarmento da Silveira, Cynara Carvalho de Abreu $\&$ Enilson Medeiros dos Santos

Universidade Federal do Rio Grande do Norte
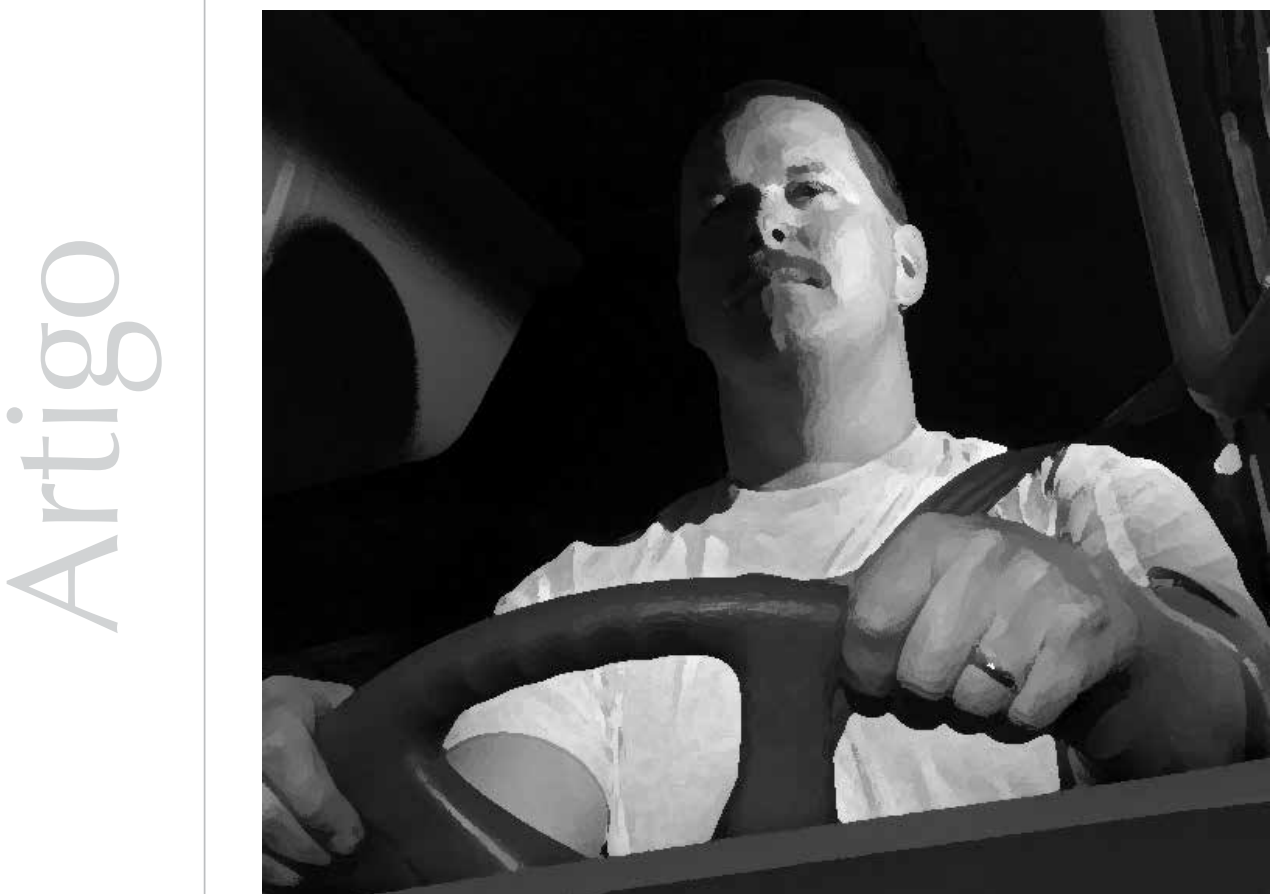
Resumo: A presente pesquisa está relacionada à análise da situação de trabalho do motorista de ônibus, e teve origem na necessidade de identificar as suas dificuldades em cumprir as tarefas para alcançar os resultados determinados por uma empresa de transporte coletivo urbano da cidade de Natal. Foram entrevistados 50 motoristas sobre nove fatores relacionados ao seu trabalho. Os resultados mostraram que os fatores trânsito, tempo de viagem, condições da via, manutenção do veículo, ambiente físico (terminal de linha), posto de trabalho e supervisão exercida constituem constrangimentos para a atividade do motorista, diferenciando o trabalho prescrito do trabalho real. Por outro lado, fatores como gostar de dirigir, o trabalho em si e os colegas de trabalho influenciam positivamente na situação de trabalho do motorista. Nas proposições dos subsistemas de administração de recursos humanos, foram encontradas como alternativas para o redimensionamento dessa atividade a possibilidade de alterações nas políticas de recrutamento e de seleção de pessoal, implementação de um sistema de avaliação de desempenho, melhorias no ambiente de trabalho, esclarecimentos sobre política salarial, exercício da supervisão do qual participem os motoristas e a redução de estressores no ambiente de trabalho.

Palavras-chave: Stress ocupacional. Satisfação no trabalho. Administração de recursos humanos. Qualidade de vida no trabalho. Condições de trabalho.

\begin{abstract}
This research is related to the analysis of the bus driver work situation, and was originated by the need to identify the difficulties of the driver in accomplishing the tasks to achieve the results determined by a public transport company in Natal. We interviewed 50 drivers on nine factors related to their work. The results showed that the factors transit, travel time, road conditions, vehicle maintenance, physical environment (bus terminal), job post and supervision are constraints to the activity of the driver distinguishing the prescribed work and the work actually done. On the other hand, factors such as enjoying driving, the work itself and being with the workmates positively influenced the drivers' working conditions. In the propositions of human resource management subsystems were found as alternatives to reform this activity the possibility of changes in the policies of staff recruitment and selection, implementing a system of performance evaluation, improvements in the workplace, information on wage policy, exercise of supervision with the participation of drivers and reduction of stressors in the workplace.
\end{abstract}

Keywords: Occupational stress. Job Satisfaction. Human resource management. Quality of work life. Working conditions.

Resumen Esta investigación está relacionada con el análisis de la situación de trabajo del conductor de autobús , y se originó en la necesidad de identificar las dificultades en el cumplimiento de las tareas para lograr los resultados determinados por una empresa de transporte urbano de Natal. Entrevistamos a 50 conductores en nueve factores relacionados con su trabajo. Los resultados mostraron que los factores de tránsito, tiempo de viaje, estado de las carreteras, mantenimiento de vehículos, el entorno físico (terminal de autobuses), puesto de trabajo y la supervisión son las limitaciones a la actividad del conductor para distinguir el trabajo prescrito y el trabajo efectivamente realizado. Por otro lado, factores como disfrutar de la conducción, el trabajo en sí y estar con los compañeros de trabajo influyeron positivamente en las condiciones de trabajo de los conductores. En las proposiciones de los subsistemas de gestión de recursos humanos fueron encontrados como alternativas para reformar esta actividad la posibilidad de cambios en las políticas de contratación y selección del personal, la implementación de un sistema de evaluación del rendimiento, las mejoras en el lugar de trabajo, la información sobre la política salarial, el ejercicio de la supervisión con la participación de los conductores y la reducción de los factores de estrés en el lugar de trabajo.

Palabras-clave: Estres ocupacional. Satisfaccion em el trabajo. Gestión de recursos humanos. Calidad de vida en el trabajo. Condiciones del trabajo.

O transporte público pode ser enquadrado dentro do setor de serviços, que é diferenciado de tantas outras atividades de trabalho no que tange à qualidade. Destaca-se como diferenciação: a intangibilidade de seus resultados, a participação do cliente na produção, a heterogeneidade dos processos e dos resultados, com alta variabilidade motivada por fatores de difícil controle, principalmente os associados ao cliente, os picos de demanda e o fato de a produção não ocorrer em ambiente controlado, pois há o deslocamento espacial. Além disso, o transporte é uma atividade-meio, e suas operações fazem parte de uma cadeia de eventos sobre a qual o cliente tem interesse no resultado final do conjunto de atividades, e não apenas no transporte propriamente dito (Rodrigues \& Sorratine, 2008). 
Nas empresas de transporte coletivo, o motorista tem um papel preponderante na percepção da qualidade do serviço de transporte público. De acordo com a Associação Nacional das Empresas de Transportes Urbanos (Cadaval, 2001), a qualidade do serviço de transporte prestado recai sobre o motorista, pois é ele quem está em contato direto com os clientes, e por isso the é atribuída a responsabilidade de proceder de acordo com os princípios éticos, técnicos e de relacionamento interpessoal desejável.

Diante dessas características, os resultados determinados pelas empresas nem sempre são alcançados por seus funcionários. As disfunções da produção de um bem ou de um serviço, assim como os resultados insatisfatórios da empresa, podem ter causas diversas, relacionadas tanto no que se refere à gestão do negócio e dos indivíduos quanto aos aspectos individuais das pessoas que executam as atividades.

Considerando os aspectos acima expostos, várias questões são instigantes para a pesquisa, e este estudo procurou compreender em que medida há diferença entre o trabalho prescrito do motorista e o trabalho real no contexto de uma empresa de transporte coletivo. Há aspectos deletérios nessa atividade? Que processos construtivos podem ser desenvolvidos para transformar a realidade do seu trabalho?

Para compreender essas questões, foi escolhido o enfoque teórico-metodológico da ergonomia da atividade.

$\mathrm{O}$ artigo tem como objetivo analisar a distância existente o trabalho prescrito e o trabalho real de motoristas de uma empresa de transporte urbano da cidade de Natal/RN.

\section{Análise da situação de trabalho: antecedentes teóricos}

Uma organização, de acordo com Guérin et al. (2001), busca alcançar seus objetivos determinando resultados que se darão através da atividade coletiva de trabalho, sendo essa atividade realizada sob condições por ela determinadas, o que constitui para o trabalhador a sua tarefa. Esta é, pois, como descreve Falzon e Sauvagnac (2007) o que se deve fazer, o que é prescrito pela organização. Guérin et al. (2001) atentam para o fato de que as condições determinadas pela organização, na maioria das vezes, não são idênticas às reais, e o resultado antecipado geralmente não é o efetivo, manifestando-se a distância entre o trabalho prescrito e o real, o que chama a atenção para as contradições presentes no ato do trabalho.

Ferreira (2000) traz seu ponto de vista acerca da distância existente entre o trabalho formalmente prescrito e o trabalho real, o que constitui uma descontinuidade fundamental, com base em duas normas: a do modelo da realidade em geral e a da atividade em particular. A tarefa frequentemente não leva em conta as particularidades dos operadores e muito menos o que pensam sobre as escolhas feitas. Ela é exterior ao operador e é imposta.

Nessa distância, Guérin et al.(2001) definem como atividade de trabalho a maneira como os resultados são obtidos e como os meios são utilizados. É uma estratégia de adaptação à situação real de trabalho, objeto da prescrição. Falzon e Sauvagnac (2007) sintetiza que a atividade é o que é de fato realizado, o que o sujeito mobiliza para efetuar a tarefa. Assim, a atividade resulta da união das prescrições da organização com as ações que o indivíduo realiza para dar conta das exigências da tarefa e com as suas características pessoais, experiência e treinamento (Abrahão, 2000). Considera-se 
também atividade aquilo que não se pode fazer, aquilo que se gostaria de ter feito, a atividade impossível, suspensa ou impedida (Silva, Barros, \& Louzada, 2011).

É no contexto da atividade que surgem os constrangimentos. Consideram-se constrangimentos as exigências estabelecidas por uma determinada atividade de trabalho que poderão gerar intensificação no seu ritmo, questões relacionadas à sua organização, repetitividade de movimento da mesma tarefa, permanência em posturas fixas, estresse, desconforto, lesões e/ou riscos de acidentes (Guerin et al., 2001).

Nos sistemas de produção, também ocorrem variabilidades, que, para Vidal (2008), referem-se a instabilidade, variação ou diversificação das condições situadas para a realização das tarefas, de modo que estas nem sempre se apresentam da mesma forma. As variabilidades devem ser geridas, estabilizadas, pelos gestores ou pelos trabalhadores.

A atividade reflete as estratégias operatórias de regulação que o trabalhador realiza para dar conta das exigências da tarefa e dos objetivos e das restrições que o mesmo coloca para si. Para Falzon e Sauvagnac (2007), é quando o trabalhador adapta sua atividade, ritmo ou modo operatório tendo em vista evitar repercussões negativas da atividade para si mesmo, atingir os objetivos da tarefa ou aprender. Estratégias de regulação, de acordo com Vidal, são as estratégias que o trabalhador usa para administrar a distância entre o trabalho prescrito e o trabalho real. As funções de regulação podem trazer efeitos positivos para a atividade quando, ao adaptála, o trabalhador desenvolve competências e tem o interesse, a satisfação e a sua utilidade no trabalho aumentados.

A situação de trabalho para a clínica da atividade, segundo Clot e Leplat (2005 como citado em Bendassolli \& Soboll, 2011), compreende a relação entre o sujeito, de um lado, e o trabalho e o meio, de outro. Guerin et al., ao tratarem da abordagem ergonômica do trabalho, consideram a dimensão pessoal e socioeconômica que todo trabalho tem, chamando de situação de trabalho o lugar onde se dá a articulação entre o caráter pessoal e o caráter socioeconômico do trabalho.

Abrahão acrescenta que as situações de trabalho variam, sendo cada uma singular e caracterizada pelas diferenças individuais, situações que são confrontadas com os mesmos objetivos e meios de trabalho, e que, desse modo, configuram-se como situações diferenciadas, dependendo do indivíduo, que possui experiência, história e formação também distintas. Pode-se dizer que as exigências, os meios de execução da tarefa e o sujeito que a executa e sua relação com os outros afetam diretamente a situação de trabalho.

Nas organizações, o trabalho é dividido, e as pessoas o executam e especializam-se no que fazem. A organização exige a vida em grupo, no qual estão presentes os interesses, os objetivos, as necessidades e as prioridades tanto organizacionais quanto grupais, que podem ser convergentes ou divergentes com os objetivos e os interesses das pessoas. Esse processo retrata a interdependência entre empresa e pessoas, requerendo, portanto, a adoção de um sistema de gestão que defina com clareza e objetividade as políticas e as práticas de recursos humanos.

Nesse contexto, vale a pena definir o que se considerou administração de recursos humanos (ARH): várias atividades integradas que atuam desde a inclusão de novas pessoas na empresa, no desenho das atividades e na forma como o desempenho será avaliado, e que definem ações para incentivar as pessoas e satisfazer suas necessidades individuais 
mais elevadas, além de definir como será realizada a capacitação e o desenvolvimento profissional das pessoas, criando condições ambientais satisfatórias, controlando a realização das atividades e verificando os resultados (Chiavenato, 2008).

Sendo as pessoas consideradas agentes primordiais no desempenho organizacional e levando em conta que se vive na chamada era da informação e em um mundo globalizado no qual a realidade laboral proporciona ao sujeito vivências tanto de sofrimento quanto de oportunidades para o seu desenvolvimento, as questões engendradas pelo trabalho têm sido estudadas e difundidas por vários autores, de diferentes correntes teóricas, a exemplo da ergonomia da atividade, com Wisner e Guerin, da clínica da atividade, com Yves Clot, e com a Psicologia social, no Brasil. Embora nessas teorias haja diversidade epistemológica, teórica e metodológica, todas possuem como objeto comum a situação de trabalho.

De acordo com Bendassolli e Soboll (2011), a Psicologia organizacional está ligada à Psicologia aplicada com vocação interventiva, que surgiu com a proposta de oferta de soluções cientificamente embasadas, via quantificação, destinadas à previsão e ao controle de comportamento. Importa, para essa vertente, o comportamento como categoria-chave para a explicação e o manejo das questões relacionadas ao desempenho a fim de se oferecer instrumentos de controle para a gestão, já que a Psicologia organizacional e do trabalho (POT) tem, em seus primórdios, fundamentos na Psicologia cognitivo-comportamental.

Ao instrumentalizar o gerenciamento dos fatores humanos no trabalho e ao promover a adaptação do sujeito aos chamados imperativos do desempenho e da eficiência, as teorias cognitivo-comportamentais são criticadas, e surge na Psicologia organizacional, com Le Guillant (1984 como citado em Bendassolli \& Soboll, 2011), uma contribuição para instituir uma abordagem clínica do trabalho, que insiste na indivisível união entre o indivíduo e seu meio e sugere que diversas manifestações patológicas são encontradas nas situações concretas vivenciadas pelo trabalhador.

Ainda de acordo com Bendassolli e Soboll, a abordagem clínica do trabalho compreende um conjunto de teorias com foco de estudo na relação entre trabalho e subjetividade. As abordagens clínicas buscam evidenciar a relação entre o trabalho e os processos de subjetivação, de forma que os conhecimentos produzidos nessa perspectiva oportunizam conscientização relativa às vivências nas relações de trabalho, visando à transformação da realidade.

Para Lima (2011), as clínicas do trabalho referem-se ao conjunto de disciplinas que abordam questões relativas à subjetividade nos contextos laborais, ou seja, às tentativas de compreender a relação entre fatores subjetivos e atividade.

A associação entre clínica e trabalho, de acordo com Bendassolli e Soboll (2011), está pautada em uma articulação do mundo psíquico com o mundo social. A clínica do trabalho tem como foco de pesquisa e intervenção a realidade vivenciada pelos sujeitos, o que a aproxima de uma clínica social, e também contempla as vivências de sofrimento ancoradas nas experiências objetivas e subjetivas de trabalho, daí a terminologia clínica. É importante ressaltar que, mesmo atenta ao sofrimento e aos aspectos deletérios do trabalho, a clínica do trabalho enfatiza não só os processos criativos e construtivos do sujeito como também sua capacidade de mobilização, de ação e de resistência face à realidade do trabalho.

Uma premissa assumida pelas clínicas do 
Trata-se de

um sujeito

com conflitos intrapsíquicos,

que não se

constitui fora da relação com o outro, como é compreendido pela abordagem psicodinâmica do trabalho, ou que se desenvolve e se afirma, por meio da atividade, no seu confronto com a realidade (Clot, 1998 como citado em Bendassolli \& Soboll, 2011). trabalho é a necessidade de lutar contra a vulnerabilidade social, contra a ocultação do real trabalho e as formas de alienação e de invisibilidade social, como comumente ocorre com os operadores de transporte coletivo urbano.

Mas, quais seriam essas clínicas do trabalho? Bendassolli e Soboll citam e discutem quatro modelos de clínicas do trabalho: a psicodinâmica do trabalho, a clínica da atividade, a psicossociologia e a ergologia.

Especificamente, a clínica da atividade que teve sua origem a partir de 1990 fundamentase na teoria de Vigotsky, Leontiev e Bakhtin, que enfatiza a busca de instrumentos que viabilizem a compreensão da situação de trabalho real para aumentar no sujeito, de acordo com Clot (como citado em Bendassolli \& Soboll, 2011, p.10), "o poder de agir sobre o mundo e sobre si mesmo, coletivamente e individualmente". Essa abordagem busca instrumentos para compreender uma situação de trabalho real a partir da articulação entre atividade e subjetividade. O objetivo da clínica da atividade não é a atividade como tal, e sim, o desenvolvimento das atividades do sujeito e seus impedimentos.

As clínicas do trabalho, embora distintas, têm pontos em comum. Bendassolli e Soboll (2011) citam como primeiro ponto o interesse pela extensão do poder de agir dos sujeitos no trabalho. Todas elas buscam criar condições psicossociais para que os sujeitos se apropriem de sua atividade de formas distintas, para que busquem enfrentar as questões ou as dificuldades nela encontradas. O segundo ponto é o entendimento do trabalho não restrito a sua institucionalização econômica, ao emprego, mas como atividade com significados.

O outro ponto é a defesa de uma teoria do sujeito, um sujeito que não pode ser equiparado a máquina que processa as informações de seu ambiente e devolve-as em forma de ações comportamentais, como ainda, segundo eles, é concebido pelas abordagens experimentais. Trata-se de um sujeito com conflitos intrapsíquicos, que não se constitui fora da relação com o outro, como é compreendido pela abordagem psicodinâmica do trabalho, ou que se desenvolve e se afirma, por meio da atividade, no seu confronto com a realidade (Clot, 1998 como citado em Bendassolli \& Soboll, 2011).

Quanto ao propósito das clínicas do trabalho, elas têm como primeiro foco de preocupação a vulnerabilidade do sujeito e dos coletivos profissionais, vulnerabilidade que pode levar à individualização e à consequente perda de referenciais compartilhados e de mal-estar no trabalho, incluindo doenças físicas, transtornos e alterações mentais e psicossociais.

As teorias clínicas do trabalho não se restringem aos aspectos nocivos do trabalho, à psicopatologia, às origens e às manifestações do sofrimento no trabalho. Elas também se interessam pela relação sujeito-trabalho, pela capacidade do sujeito de criação, reinvenção, superação das dificuldades colocadas pelo trabalho real, por compreender os processos de resistência e de superação por parte dos coletivos de trabalho.

Quanto à Administração de Recursos Humanos - ARH, Limongi-França (2009) a compreende com foco na Psicologia social. Para ela, a pedra fundamental da gestão de pessoas está na contribuição conceitual e prática para uma vida humana mais saudável, com resultados legítimos de produtividade, qualidade, desenvolvimento e compatibilidade sustentável. Trata-se de um enfoque nos processos comportamentais integrados aos aspectos administrativos da empresa.

Para Milkovich e Boudreau (2000), a ARH 
envolve decisões integradas que formam as relações de trabalho e influenciam a empresa e seus empregados a atingir seus objetivos. A introdução de sistemas integrados de gestão é também considerada por Ribeiro (2006) como um fator crítico de sucesso para a organização. Em relação às várias atividades da ARH, Muchinsky (2004) chama a atenção para o fato de que um recrutamento insatisfatório limita muito a qualidade das pessoas disponíveis para contratação. Já o valor da avaliação de desempenho para a empresa e para o empregado é defendida por Spector (2002).

Sobre a influência dos fatores pessoais na atividade de trabalho, para Ferreira, a tarefa frequentemente não leva em conta as particularidades dos operadores e muito menos o que pensam sobre as escolhas feitas. Elas são exteriores ao operador e são impostas.

Ao tratar da vivência do estresse relacionado ao trabalho, Johnson et al. (como citado em Rossi, Quick \& Perrewe, 2009) assinalam que uma série de estressores relacionados ao trabalho tem sido associada a maior probabilidade de um indivíduo vivenciar as consequências negativas do stress.

Ao pensar no trabalho dos motoristas de ônibus, Santos Júnior (2003) observou que tais profissionais estão expostos a uma enorme gama de fatores nocivos (físicos, químicos, biológicos e ergonômicos), os quais podem produzir todas as categorias de doenças relacionadas ao trabalho. Battiston, Cruz e Hoffmann (2006), ao caracterizar as condições em que trabalham e a saúde de motoristas de transporte coletivo urbano na cidade de Florianópolis/SC, concluíram que as condições de trabalho e a saúde dos motoristas de transporte coletivo urbano podem ser consideradas fontes dos distúrbios orgânicos ou psíquicos que acometem esses profissionais. Gobel et al. (1998, p. 22 como citado em Gonçalves, 2003) consideram que os possíveis causadores do estresse são os passageiros, o próprio motorista e o veículo.

A presente pesquisa se apropria de cada um desses conceitos para caracterizar um serviço de transporte coletivo urbano. Assim, ao analisar a situação de trabalho de motoristas de uma empresa de ônibus urbano, foi possível identificar as contradições presentes nesse contexto que geram custo para a empresa e que se refletem em vivências de mal-estar e de bem-estar para os motoristas.

\section{Contexto e relevância da pesquisa}

Estudar o transporte público por ônibus pode contribuir para a melhoria do trabalho de uma classe de trabalhadores e para a diminuição das consequências de ineficiência do transporte público.

O transporte público é um setor importante para as cidades e para a sociedade, pois possibilita a mobilidade da maioria dos cidadãos, tornando a cidade socialmente inclusiva. Dentre tantas funções do transporte público, destaca-se o deslocamento de funcionários de casa para o trabalho, funcionando como insumo para o setor produtivo industrial e de serviço, condição essa fundamental para a cidade ser economicamente eficiente. É também um importante setor gerador de empregos; na cidade de Natal, por exemplo, o transporte coletivo urbano gera aproximadamente 3.900 empregos diretos (Secretaria Regional do Trabalho do Rio Grande do Norte, 2011).

O transporte público de passageiros ineficiente, além de dificultar a mobilidade de grande parte da população das cidades, provoca a migração de outra parcela de cidadãos para o transporte individual (outros modais como automóvel, moto, bicicleta, andar a pé) e abre espaço para o transporte 
clandestino (ou ilegal). Essa situação contribui para o aumento do congestionamento das vias, aumenta a poluição ambiental causada pelo grande volume de veículos em circulação e propicia o aumento da violência no trânsito (Associação Nacional das Empresas de Transportes Urbanos, 2008).

\section{Método}

Este estudo tem caráter descritivo e exploratório e utiliza-se do método estudo de caso. Para tanto, estudou-se, em uma das sete empresas de ônibus urbano da cidade de Natal/RN, a situação de trabalho de motoristas.

O estudo de caso consiste em uma análise aprofundada de um ou mais objetos (casos), para permitir seu amplo e detalhado conhecimento (Gil, 1996).

Decidiu-se pela participação dos motoristas como sujeitos de seu próprio estudo e em seu local de trabalho, como recomenda Wisner (1987), sendo que as entrevistas não foram feitas por convocação, mas por um convite, de modo a garantir princípios éticos, como as consequências dos relatos do motoristas junto aos gestores da empresa, como sustenta Mendes (2007), de modo que as entrevistas não puderam ser realizadas com todos eles nem por amostragem aleatória.

Como se tratou de um grupo submetido a um mesmo modelo de organização do trabalho, foi estabelecido que deveriam ser ouvidos motoristas em todas as linhas de operação da empresa, e, quando foi feito o levantamento do número de motoristas por linha, verificou-se que a menor linha operava com quatro motoristas, e a maior, com vinte e quatro (Tabela 1). Para definir o número do motorista entrevistado, foi levado em consideração que deveriam ser ouvidos no mínimo dois motoristas da menor linha, $50 \%$ da menor linha, e estabelecido, para que houvesse proporcionalidade, $20 \%$ dos motoristas das maiores linhas.

Foi iniciada a coleta de informações e de dados com gerentes e funcionários da administração da empresa e, posteriormente, com os motoristas. Junto aos gerentes e funcionários, foram feitos um levantamento e a identificação de fontes documentais (relatório, histórico, normas). Com os motoristas, as entrevistas foram realizadas com base em roteiro de perguntas pré-estabelecidas pelo pesquisador, a que os entrevistados responderam, e o pesquisador anotou as respostas ao mesmo tempo em que as gravava.

As entrevistas foram feitas na medida em que os motoristas chegavam ao terminal da linha, entre uma viagem e outra, no intervalo de repouso ou no término da jornada. Eles foram abordados pela pesquisadora, que explicou o objetivo da pesquisa e o que era o Termo de Consentimento Livre e Esclarecido. Com aqueles que concordaram, as entrevistas foram realizadas no mesmo momento da abordagem ou posteriormente, em horário agendado, e as respostas foram anotadas, gravadas e transcritas. À medida que as entrevistas eram realizadas, era observado o percentual de motoristas da linha. Quando era alcançado o percentual de entrevistas estimado para cada linha, o pesquisador deslocava-se para outro terminal.

A organização, o tratamento e a análise dos dados foram realizados na forma de banco de dados por meio de uma planilha criada no Excel, no qual as linhas se referiam aos 50 motoristas entrevistados, e as colunas, aos itens avaliados por eles, que foram agrupados em nove fatores: trânsito, tempo de viagem, condições da via, manutenção do veículo, ambiente físico (terminal de linha), posto de trabalho, supervisão exercida, fatores satisfatórios e insatisfatórios. As respostas foram somadas, tabuladas em percentuais e apresentadas em forma de tabelas. Já as 
duas perguntas abertas, o que causa satisfação e̊ insatisfação no trabalho, foram analisadas pela frequência das respostas, já que cada entrevistado poderia elencar mais de um item de satisfação ou de insatisfação.

\section{Lócus da pesquisa}

A empresa onde foi realizada a pesquisa é uma das 7 (sete) empresas que têm concessão para operar na cidade de Natal/RN; foi fundada em 14/09/1984, e tem, portanto, 26 anos de atuação no mercado e uma frota de 79 (setenta e nove) ônibus. Possui um efetivo médio de 388 (trezentos e oitenta oito) funcionários; destes, 159 (cento e cinquenta e nove) são motoristas, sendo que apenas 124 (cento e vinte e quatro) trabalham diretamente na operação do serviço de transporte coletivo.

As informações sobre a empresa foram obtidas através de entrevista, com tópicos, junto ao gerente administrativo, ao chefe de setor pessoal, à assistente social e ao chefe do departamento de tráfego. As informações fornecidas verbalmente foram gravadas e posteriormente transcritas. Foram utilizados também documentos, registros e feitas observação in loco. Já os motoristas foram entrevistados nos terminais de linha de onde operam, a partir de um roteiro estruturado.

A referida empresa, que transporta em torno de 1.100 .000 (um milhão e cem mil) passageiros/ mês, opera em 11 (onze) linhas, e cada linha tem uma numeração que identifica seu destino, um tempo de viagem estabelecido para cada percurso completo, número de veículos operante na linha e número de motorista escalado em cada uma delas, conforme a Tabela 1.

Tabela 1. Linhas, destino, no de veículos e de motoristas por linha, duração da viagem

\begin{tabular}{llccc}
\hline No da Linha & Destino & $\begin{array}{c}\text { No de } \\
\text { veículos }\end{array}$ & $\begin{array}{c}\text { No de } \\
\text { motoristas }\end{array}$ & $\begin{array}{c}\text { Tempo de } \\
\text { viagem (min.) }\end{array}$ \\
\hline 50 & Serrambi/Santa Catarina & 12 & 24 & 118 \\
51 & Rocas/Pirangi (via Praça) & 10 & 20 & 95 a 100 \\
52 & Rocas/Pirangi (via Alecrim) & 10 & 16 & 95 a 100 \\
$7.461 / 7.462$ & Circular Ponta Negra/N. & 2 & 4 & 40 \\
65 & Parnamirim & 7 & 14 & 90 a 105 \\
85 & Serrambi/Quintas (via praça) & 2 & 4 & 80 \\
$104 / 105$ & Soledade/Petrópolis & 11 & 21 & 95 a 110 \\
739 & (via ponte de todos) & 8 & 15 & 95 a 110 \\
$106 / 107$ & Eucaliptos/Ribeira (via praça) & 3 & 6 & 95 a 110 \\
& N. Parnamirim/Ribeira & & & \\
& (via M. Lacerda) & & & \\
& N. Parnamirim/Ribeira & & & \\
& (via Abel Cabral) & & & \\
\hline
\end{tabular}

Fonte - Setor de tráfego da empresa 


\section{Participantes}

A população da pesquisa consiste nos motoristas de uma empresa de ônibus urbano da cidade de Natal/RN. As entrevistas foram realizadas por acessibilidade, e representaram $40 \%$ da população de motoristas da empresa pesquisada, o que correspondeu a 50 dos 124 motoristas em atividade em dezembro de 2010.

\section{Instrumentos}

Para elaborar o instrumento de coleta de dados, o roteiro de entrevista, inicialmente tomou-se conhecimento das tarefas do cargo do motorista de acordo com a empresa, e, posteriormente, observou-se o seu ambiente de trabalho e levantaram-se os itens que estão presentes na atividade desse profissional. O instrumento tem início com perguntas relacionadas ao perfil sociodemográfico do motorista (estado civil, forma de moradia, quantidade de filhos, uso de bebida alcoólica, tempo de permanência no emprego atual e tempo de deslocamento de casa para o trabalho). As demais perguntas foram elaboradas em relação a cada item que os pesquisadores consideraram estar presente na atividade do motorista: o tempo de viagem planejado pela empresa, a interferência do passageiro, a supervisão direta, a manutenção do veículo, o trânsito, as condições da via, o posto de trabalho e as condições do ambiente de trabalho (terminal) para descanso, alimentação e necessidades fisiológicas. A fim de cobrir outros itens não previstos na elaboração das perguntas do questionário, foram incluídas duas questões abertas sobre fatores considerados satisfatórios ou insatisfatórios para o motorista.

Na realização das entrevistas, o pesquisador embasou-se nas orientações fornecidas por Bauer e Gaskell (2002), que sugerem: testar o gravador antes do início de cada entrevista, garantir a confidencialidade das informações, realizar um comentário sobre a pesquisa, fazer o pedido para gravar justificando ser essa uma ajuda à memória e agradecer pelo fato de a pessoa ter concordado em falar, manter o foco da atenção na escuta e no entendimento do que está sendo dito, e não na escrita ou no roteiro da entrevista, dar ao entrevistado tempo para pensar, por isso, as pausas das respostas não devem ser preenchidas com outras perguntas, procurar terminar a entrevista com uma nota positiva e agradecer ao entrevistado.

O roteiro da entrevista foi elaborado com uma sequência de perguntas que tinha uma finalidade, nesse caso, a de ouvir o motorista sobre a sua atividade de trabalho, de modo que as respostas, mesmo as subjetivas, pudessem ter um tratamento de classificação quantitativa.

\section{Procedimento de coleta de dados}

Após a aprovação da pesquisa pelo Comitê de Ética da Universidade Federal do Rio Grande Norte, Parecer no. 313/2008, tiveram início os procedimentos de coleta de dados na empresa-alvo do estudo em dezembro de 2010. Todas as entrevistas foram realizadas no período de dezembro de 2010 a fevereiro de 2011.

As entrevistas foram realizadas nos quatro terminais de ônibus onde a empresa opera com suas linhas, em lugar reservado, porém aberto, de modo que havia outros motoristas ou despachantes que por ali passavam ou permaneciam e podiam escutar a conversa.

Os motoristas que responderam à entrevista foram escolhidos pela ordem de chegada ao terminal no seu horário de intervalo, e dentre aqueles que, ao serem abordados e esclarecidos pelo Termo de Consentimento Livre Esclarecido, concordassem em responder às perguntas.

Quanto à realização da entrevista, as perguntas foram feitas pelo pesquisador, que anotava as respostas ao mesmo tempo em que eram gravadas, considerando que se tratava de um ambiente com ruído causado pelo barulho dos ônibus que chegavam e partiam. Diariamente, as entrevistas realizadas foram transcritas e impressas.

\section{Procedimento de análise dos dados}

As respostas dos participantes foram transcritas 
e organizadas na forma de banco de dados por meio de uma planilha criada no Excel, na qual as linhas, numeradas de 1 a 50, referiam-se aos 50 motoristas entrevistados, e as colunas, aos itens por eles avaliados, agrupados em fatores. As respostas foram tabuladas em percentuais e apresentadas em forma de tabelas. Nas perguntas abertas, um motorista poderia dar mais de uma resposta para uma pergunta, e, por isso, foram analisadas pela sua frequência.

As respostas foram comparadas ao trabalho prescrito para o motorista pela empresa conforme a Tabela 2 - Ficha de funções. Nessa ficha, estão descritas as atribuições e as responsabilidades do motorista e como ele deve agir em determinadas situações, a sequência em que as tarefas devem ser realizadas durante uma jornada de trabalho e o perfil desejado do seu ocupante.

Tabela 2 - Ficha de funções do motorista de ônibus urbano

\section{Ficha de funções}

\section{Função do cargo de motorista}

Transportar os clientes da empresa em seus veículos, através dos itinerários determinados pelo órgão gestor, obedecendo às normas definidas através do regulamento da SEMOB (Decreto no 2.812/83) e do DER/RN

\section{Descrição das tarefas}

1. Vistoriar o veículo na garagem ou no terminal da linha, antes do início da utilização do mesmo, informando ao pessoal do plantão ou despachante as avarias nele existentes;

2. Conferir toda a documentação do veículo antes do início da sua jornada de trabalho, informando ao plantonista/despachante a ausência das mesmas;

3.Conferir toda a estrutura de segurança do veículo, como triângulo, extintor, etc. informando ao plantonista/despachante a ausência de qualquer um desses equipamentos;

4.Verificar os níveis de óleo e água do veículo antes do início da operação com o mesmo;

5.No turno da manhã, antes do início de sua operação, conduzir o veículo ao terminal de origem de suas viagens;

6. Realizar todas as viagens definidas no Quadro de Horário de sua linha, transportando todos os clientes da empresa, através dos itinerários determinados pelo órgão gestor, atendendo aos sinais de embarque e desembarque de todos os usuários que se encontrarem fora e dentro do ônibus, nas paradas já pré-determinadas (apresentar-se corretamente uniformizado e identificado, prestar as informações necessárias aos usuários, colaborar com a fiscalização do órgão gerencial e dos demais órgãos incumbidos de fiscalizar o transporte, dirigir o veículo de modo a não prejudicar a segurança e o conforto dos usuários, manter velocidade compatível com o estado das vias, respeitados os limites legais, evitar freadas bruscas e outras situações propícias a acidentes, não movimentar o veículo sem que estejam fechadas as portas, não fumar, quando na direção, não ingerir bebidas alcoólicas em serviço, nos intervalos da jornada ou antes de assumir a direção, comunicar à garagem quando ocorrerem indícios de defeito mecânico que possa pôr em risco a segurança dos usuários, recolhendo o veículo quando autorizado, diligenciar a obtenção de transporte para os usuários, em caso de avaria e interrupção da viagem, prestar socorro aos usuários feridos em caso de sinistro, respeitar os horários programados para a linha, dirigir com cautela especial à noite e em dias de chuva ou de pouca visibilidade, atender aos sinais de parada nos pontos estabelecidos, não embarcar ou desembarcar passageiros fora dos pontos estabelecidos, recusar o transporte de animais, plantas de médio e grande porte, material inflamável ou corrosivo e outros materiais que possam comprometer a segurança ou o conforto dos usuários, respeitar as normas disciplinares da empresa e as determinações da fiscalização, e, quando necessário, poderá solicitar a intervenção da autoridade policial para retirar do veículo o usuário faltoso;

7. Após sua jornada de trabalho, entregar o veículo ao plantonista/despachante nas mesmas condições do seu recebimento;

8. No turno da tarde, após sua jornada de trabalho, recolher o veículo à garagem;

9. Obedecer às normas da empresa;

10.Assinar a guia de serviço no início de sua jornada de trabalho.

Perfil indispensável ao cargo

- Carteira de Habilitação Tipo D;

- Ter no mínimo 2 (dois) anos de experiência comprovada nas atividades de transporte coletivo ou caminhão.

\section{Perfil desejável ao cargo}

- Idade entre 25 a 45 anos;

- Morar nas proximidades da garagem;

- 2. o grau completo.

Formação necessária

- Curso de Condutores de Veículos de Transporte Coletivo de Passageiros (Resolução n 168 do CONTRAN);

- Curso de Atualização para Condutores de Veículos de Transporte Coletivo de Passageiros a cada 5 anos, na renovação da CNH. 
A discussão dos resultados foi fundamentada nos processos da Administração de Recursos Humanos - ARH.

\section{Resultados}

Os resultados das entrevistas realizadas com 50 motoristas são apresentados por blocos de fatores e relacionados aos processos da administração de recursos humanos. Esses resultados foram assim classificados: 1) fatores motivacionais e pessoais relacionados aos processos de entrada e de saída das pessoas na organização e de aperfeiçoamento, 2) fatores da carga de trabalho aos processos relativos ao desempenho das pessoas, 3) fatores ligados à satisfação e à insatisfação no trabalho aos processos de recompensar pessoas, 4) fatores relacionados às condições físico-ambientais aos processos de permanência das pessoas no trabalho e 5) fatores relacionados à gestão do trabalho ao processo de monitorar pessoas no trabalho.

1 - Fatores motivacionais e pessoais

Tabela 3. Motivo para ser motorista

\begin{tabular}{llllll}
\hline $\begin{array}{l}\text { Influência de } \\
\text { parente que } \\
\text { o iniciou em } \\
\text { caminhão }\end{array}$ & $\begin{array}{l}\text { Sempre } \\
\text { gostou de } \\
\text { dirigir }\end{array}$ & $\begin{array}{l}\text { Aprendeu } \\
\text { a dirigir no } \\
\text { trabalho } \\
\text { quando exercia } \\
\text { outra atividade }\end{array}$ & $\begin{array}{l}\text { Aprendeu } \\
\text { a dirigir no } \\
\text { Exército }\end{array}$ & $\begin{array}{l}\text { Não teve } \\
\text { opçãa na } \\
\text { vida }\end{array}$ & $\begin{array}{l}\text { Achava que } \\
\text { era uma boa } \\
\text { atividade }\end{array}$ \\
\hline 25 & 7 & 7 & 5 & 4 & 2 \\
$50 \%$ & $14 \%$ & $14 \%$ & $10 \%$ & $8 \%$ & $4 \%$ \\
\hline
\end{tabular}

Tabela 4. O que pensa em fazer quando se aposentar

\begin{tabular}{lllll}
\hline Não sabe & Descansar & $\begin{array}{l}\text { Continuar } \\
\text { trabalhando } \\
\text { na empresa }\end{array}$ & $\begin{array}{l}\text { Continuar trabalhando, } \\
\text { porém em outra } \\
\text { atividade }\end{array}$ & $\begin{array}{l}\text { Ter negócio } \\
\text { próprio }\end{array}$ \\
\hline 26 & 12 & 5 & 5 & 2 \\
$52 \%$ & $24 \%$ & $10 \%$ & $10 \%$ & $4 \%$ \\
\hline
\end{tabular}


Tabela 5. Fatores pessoais

\begin{tabular}{lllllllll}
\hline \multicolumn{2}{c}{$\begin{array}{c}\text { Estado civil } \\
\text { de }\end{array}$} & Moradia & & & Filhos & $\begin{array}{l}\text { Bebida } \\
\text { Alcóolica }\end{array}$ \\
\hline Casado empresa \\
\hline
\end{tabular}

Quanto ao motivo para ser motorista, observa-se nas respostas da maioria dos entrevistados que eles se tornaram motoristas por influência familiar ou por tendência pessoal, sendo essa formação adquirida no caminhão, na empresa onde trabalhou na época de sua formação ou no exército. Não houve nenhuma resposta que apontasse uma escola de qualificação, um curso formal ou processo sistemático que promovesse a aquisição da habilidade de dirigir.

Em relação ao futuro, 52\% dos entrevistados não planejaram seu futuro, e $34 \%$ demonstram cansaço com a atividade atual, planejando descansar ou trabalhar em outra atividade na época da aposentadoria.

O perfil predominante dos motoristas entrevistados é o de pessoas casadas oficialmente, $80 \%$ deles não têm gastos com aluguel, porque moram em casa própria ou cedida, têm em média 2 filhos, $72 \%$ deles fazem uso de bebida alcoólica com alguma frequência e têm uma permanência média na empresa de 4,6 anos.

2 - Fatores relacionados à carga de trabalho

Tabela 6. Tempo de viagem, o passageiro, manutenção do veículo, trânsito e via

\begin{tabular}{|c|c|c|c|c|c|c|c|c|c|c|}
\hline $\begin{array}{l}\text { Tempo de } \\
\text { viagem } \\
\text { planejado }\end{array}$ & & $\begin{array}{l}\text { Passageiro x } \\
\text { desempenho } \\
\text { do motorista }\end{array}$ & & & $\begin{array}{l}\text { Manutenção } \\
\text { do veículo }\end{array}$ & & Trânsito & & $\begin{array}{l}\text { Condi } \\
\text { da via }\end{array}$ & ões \\
\hline Suficiente & $\begin{array}{l}\text { Insuficien- } \\
\text { te (alguns } \\
\text { ou } \\
\text { todos os } \\
\text { horários) }\end{array}$ & $\begin{array}{l}\text { Interfere } \\
\text { positivamente }\end{array}$ & $\begin{array}{l}\text { Não } \\
\text { interfere }\end{array}$ & $\begin{array}{l}\text { Interfere } \\
\text { negativa- } \\
\text { mente }\end{array}$ & Atende & $\begin{array}{l}\text { Não } \\
\text { Atende }\end{array}$ & Dificulta & $\begin{array}{l}\text { Não } \\
\text { interfere }\end{array}$ & Boa & Ruim \\
\hline 2 & 48 & 5 & 27 & 18 & 20 & 30 & 49 & 1 & 12 & 38 \\
\hline 4 & $96 \%$ & $10 \%$ & $54 \%$ & $36 \%$ & $40 \%$ & $60 \%$ & $98 \%$ & $2 \%$ & $24 \%$ & $76 \%$ \\
\hline
\end{tabular}


na ficha de funções - Tabela 2: "Realizar todas as viagens definidas no Quadro de Horário de sua linha, transportando todos os clientes da empresa, através dos itinerários determinados pelo órgão gestor, atendendo aos sinais de embarque e desembarque de todos os usuários que se encontrarem fora e dentro dos nossos coletivos, nas paradas já pré-determinadas".

Esse item foi considerado por $96 \%$ dos motoristas entrevistados como insuficiente em pelo menos uma das viagens que compõem sua jornada diária de trabalho. Assim, o tempo de viagem insuficiente constitui uma variabilidade que influencia a ocorrência entre o que é prescrito e o que é realizado, de acordo com Trierweiller et al. (2007).

Sendo o tempo de viagem insuficiente uma variável constante no trabalho do motorista, ele passa a constituir um constrangimento da atividade por tornar-se uma exigência estabelecida pela própria atividade impossível de ser cumprida, segundo Guerin et al. (2001). Para atingir os objetivos estabelecidos pela empresa, o motorista, com os meios de que dispõe e levando em conta seu estado interno e seus conhecimentos, elabora estratégias, chamadas por Vidal (2008) de regulação, que são utilizadas para se adaptar a essa exigência, que, para Guerin et al. (2001), poderá gerar intensificação no seu ritmo, estresse, desconforto, lesões e/ou riscos de acidentes.

A interferência do passageiro na atividade do motorista foi avaliada como negativa, ou seja, como um fator que dificulta o desenvolvimento de sua atividade, para $36 \%$ dos entrevistados. Para um pouco mais da maioria, 54\% dos entrevistados, o passageiro não interfere no desenvolvimento de sua atividade, e um pequeno grupo de $10 \%$ de motoristas vê o passageiro como fonte positiva no desenvolvimento do seu trabalho.

A manutenção do veículo, que se refere às condições mecânicas do veículo e ao atendimento à ordem de serviço solicitada pelo motorista, é considerada insatisfatória para $60 \%$ dos entrevistados.

As condições da via são consideradas ruins para $76 \%$ dos entrevistados. Os buracos, as ondulações e a falta de sinalização das vias foram as características citadas pelos motoristas ao classificá-las como ruins.

O trânsito foi considerado por $98 \%$ dos motoristas entrevistados como fator que interfere negativamente no desenvolvimento de sua atividade. Assim, pela frequência das respostas, o trânsito e o tempo de viagem foram considerados os dois fatores mais negativos para o desenvolvimento da atividade do motorista.

Verificou-se que o trânsito, o tempo de viagem, as condições da via e a manutenção do veículo são considerados inadequados para o desenvolvimento de sua atividade por pelo menos $60 \%$ dos motoristas, e a relação com o passageiro, por $36 \%$ dos entrevistados. Desse modo, tais fatores constituem constrangimentos para a atividade do motorista que diferenciam o trabalho prescrito do trabalho real.

Ao considerar os constrangimentos como as exigências estabelecidas pela atividade de trabalho, Guerin et al. (2001) consideram que estes poderão gerar intensificação no seu ritmo, questões relacionadas à sua organização, repetitividade de movimento da mesma tarefa, permanência em posturas fixas, estresse, desconforto, lesões e/ou riscos de acidentes.

3 - Fatores ligados à satisfação e à insatisfação no trabalho 
Tabela 7. O que traz satisfação no trabalho

\begin{tabular}{llc}
\hline Item & Fator & Frequência \\
\hline 1 & Gostar de dirigir & 18 \\
2 & O trabalho em si & 11 \\
3 & Os colegas de trabalho & 5 \\
4 & Sustentar os filhos através do trabalho & 2 \\
5 & Trabalhar com o público & 2 \\
6 & Gostar da empresa & 2 \\
7 & Reconhecimento do trabalho pelo passageiro & 1 \\
8 & Terminar a jornada em paz & 1 \\
9 & Trabalhar com carro, linha e horário certos & 1 \\
10 & Ajudar a levar as pessoas & 1 \\
11 & Dirigir um carro novo & 1 \\
12 & NULO & 5 \\
\hline
\end{tabular}

Tabela 8. O que traz insatisfação no trabalho

\begin{tabular}{llc}
\hline Ítem & Fator & Frequência \\
\hline 1 & Salário defasado & 14 \\
2 & O trânsito & 11 \\
3 & $*$ Tratamento do setor de tráfego & 10 \\
4 & $* *$ O passageiro & 7 \\
5 & Dobrar ou dar a viagem a mais e não receber em dinheiro & 6 \\
6 & Pagar por avarias ou quebra de peças do veículo & 4 \\
7 & Dobrar e/ou dar viagem a mais & 3 \\
8 & Tempo de viagem curto & 3 \\
9 & Trocar o motorista de carro, linha ou horário sem consulta & 2 \\
10 & As condições mecânicas do carro em que trabalha & 2 \\
11 & Falta de reconhecimento do trabalho & 2 \\
12 & A anotação no cartão de ponto não corresponder ao tempo real trabalhado & 1 \\
13 & Semáforos dessincronizados & 1 \\
14 & Receber o salário na empresa. Deveria ser cartão de banco & 1 \\
15 & Calor & 1 \\
16 & $* * *$ Instabilidade do emprego & 1 \\
17 & A OS - Ordem de Serviço não ser atendida pela manutenção & 1 \\
18 & A empresa não dar chance para empregar um familiar do motorista & 1 \\
19 & Jornada de trabalho & 1 \\
20 & NULO & 5 \\
\hline
\end{tabular}

* "Falta de reconhecimento do nosso trabalho", "A forma como os chefes tratam os motoristas", "Não ter uma pessoa para escutar, orientar, o motorista", "Ser mal compreendido pelos superiores", "Esperar muito tempo para ser atendido no setor de tráfego", "Ser punido porque se recusa a dar uma viagem a mais", "Somos tratados como cachorro".

** Reclama, não reconhece o trabalho do motorista, não sabe usar o transporte coletivo.

*** “A pessoa não pode fazer um financiamento porque não sabe se vai estar empregado amanhã". 
Quanto aos fatores que trazem satisfação e insạtisfação no trabalho, alguns motoristas listaram mais de um fator, citaram apenas aqueles que traziam satisfação, citaram apenas os que traziam insatisfação, e outros não opinaram.

Os fatores considerados mais satisfatórios e, portanto, assinalados com maior frequência pelos entrevistados foram: gostar de dirigir, o trabalho em si e os colegas de trabalho. Esses fatores estão intrinsecamente ligados ao próprio motorista, independendo, portanto, das tarefas prescritas pela empresa. Nesse sentido, observa-se, conforme Lima (2011), a presença de questões relativas à subjetividade nos contextos laborais, ou seja, a relação entre fatores subjetivos e atividade, e também segundo Clot e Leplat (2005 como citado em Bendassolli \& Soboll, 2011), para quem a situação de trabalho compreende a relação entre o sujeito, de um lado, e o trabalho e o meio, de outro.

Quanto aos fatores considerados insatisfatórios no trabalho, o salário defasado foi citado com maior frequência, e, além desse, ainda foram citados como insatisfatórios os seguintes fatores: o tratamento do setor de tráfego, dobrar ou fazer uma viagem a mais e não receber em dinheiro, pagar por avarias ou quebra de peças do veículo, trocar o motorista de carro, linha ou horário sem consulta, falta de reconhecimento do trabalho, anotação no cartão de ponto não corresponder ao tempo real trabalhado, semáforos dessincronizados, receber o salário na empresa, calor, instabilidade no emprego, a ordem de serviço não ser atendida pela manutenção, a empresa não dar chance para empregar um familiar do motorista e jornada de trabalho. Se, de acordo com Limongi-França, a remuneração vai além do aspecto financeiro, atentar para esses outros aspectos vai refletir positivamente na situação de trabalho do motorista.

4 - Fatores relacionados às condições físico-ambientais

Tabela 9. Deslocamento, posto de trabalho e como se alimentam

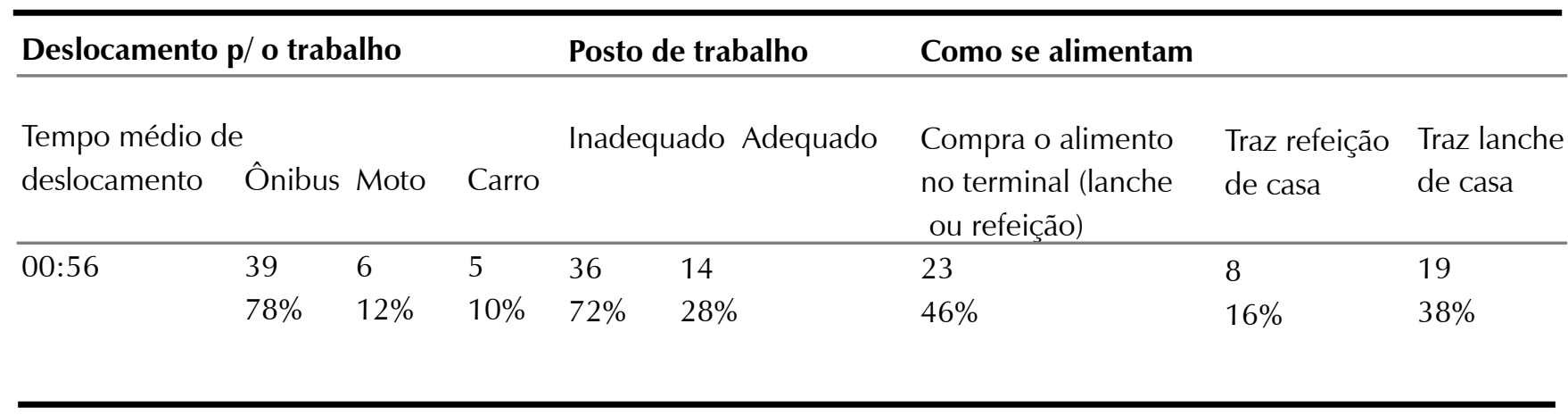

O tempo gasto com o deslocamento de casa para o trabalho compõe a jornada de trabalho e interfere na carga de trabalho. O tempo médio de deslocamento dos entrevistados de casa para o trabalho é de cinquenta e seis minutos, perfazendo uma jornada de trabalho diária média de nove horas e quatorze minutos, tendo ainda que se considerar, de acordo com Wisner (1987), que o horário e as condições nas quais a espera e o próprio transporte são feitos implicam o aumento da carga global de trabalho.

Quanto ao posto de trabalho, 72\% consideram que é inadequado, dada a presença de ruído, do calor e das condições do assento. 
Quase metade, ou seja, $46 \%$ dos entrevistados̊ compram seu alimento no terminal de ônibus, e 54\% trazem lanche ou refeição de casa, perrmanecendo com o alimento no ônibus, sem acondicionamento adequado, até a hora do consumo. É importante considerar ainda que a forma e o tempo em que esses alimentos são preparados, manipulados e acondicionados podem gerar desconforto e adoecimento, contribuindo de modo determinante para a precarização da saúde dos motoristas.

As condições do espaço físico de onde o motorista exerce suas atividades, repousa nos intervalos da atividade, alimenta-se, atende suas necessidades fisiológicas, encontra-se com os colegas de trabalho e com seu superior imediato reflete-se na carga de trabalho e contribui de modo determinante para a situação laboral.

Tabela 10. Ambiente físico (terminal de ônibus)

\begin{tabular}{llllllll}
\hline \multicolumn{3}{l}{ Serrambi } & \multicolumn{3}{c}{ Cidade Verde } & Rocas & Soledade \\
\hline Bom & Ruim & Bom & Ruim & Bom & Ruim & Bom & Ruim \\
3 & 8 & 8 & 12 & 2 & 15 & 1 & 1 \\
$27 \%$ & $73 \%$ & $40 \%$ & $60 \%$ & $12 \%$ & $88 \%$ & $50 \%$ & $50 \%$ \\
\hline
\end{tabular}

O terminal de Serrambi foi avaliado por $73 \%$ dos motoristas entrevistados como ruim, o de Cidade Verde, por $60 \%$ dos entrevistados, o das Rocas, por $88 \%$ dos entrevistados, e o de Soledade, por $50 \%$ dos entrevistados. Fatores como calor, disposição e higiene dos banheiros, o pagamento sob rateio pela água potável e a presença de desocupados no mesmo ambiente foram as queixas mais comuns relatadas pelos entrevistados.

Pela avaliação dos motoristas entrevistados, pode-se concluir que o local de trabalho desses motoristas é precário e inadequado.

5 - Fatores relacionados à gestão do trabalho

Tabela 11. Supervisão dos fiscais do setor de tráfego e do terminal

\begin{tabular}{llllll}
\hline \multicolumn{3}{l}{ Setor de tráfego } & \multicolumn{3}{l}{ Fiscal de terminal } \\
\hline Facilita & Dificulta & Indiferente & Facilita & Dificulta & Indiferente \\
16 & 23 & 11 & 31 & 10 & 9 \\
$32 \%$ & $46 \%$ & $23 \%$ & $62 \%$ & $20 \%$ & $18 \%$ \\
\hline
\end{tabular}

Quase metade dos motoristas entrevistados - $46 \%$ avaliaram que a forma como o pessoal do setor de tráfego exerce a supervisão sobre eles dificulta seu desempenho, como também o item tratamento do setor de tráfego foi avaliado como fator com terceira maior frequência de insatisfação quando foram perguntados que fatores causam insatisfação no trabalho. Eles justificaram: - Falta de reconhecimento do nosso trabalho; - A forma como os chefes tratam os motoristas; - Não ter uma pessoa para escutar, orientar, o motorista; - Ser mal compreendido pelos superiores; Esperar muito tempo para ser atendido no setor de tráfego; - Ser punido porque se recusa a dar 
uma viagem a mais; - Somos tratados como caçhorro. Já sobre a supervisão exercida pelos fiscais de terminal, apenas $20 \%$ avaliaram que suas ações dificultam seu trabalho.

A gestão do trabalho merece atenção, pois, de acordo com Wisner, todas as atividades, inclusive o trabalho, têm pelo menos três aspectos: físico, cognitivo e psíquico. Esses três aspectos estão sempre presentes nas atividades, e cada um deles pode determinar uma sobrecarga ou sofrimento. Eles se inter-relacionam, e a sobrecarga de um dos aspectos é acompanhada de uma carga também elevada nos outros dois campos.

\section{Conclusão}

Pelos resultados obtidos, foi identificada a existência de variabilidades que constituem-se em diferenças entre diversas tarefas do trabalho prescrito na Tabela 2 - Ficha de funções do motorista de ônibus urbano e o trabalho real. Essas diferenças estão descritas na Tabela 12.

Tabela 12. Diferenças entre o trabalho formalmente prescrito e o trabalho real

\begin{tabular}{l}
\hline Tarefa prescrita \\
-Dirigir o veículo de modo a não \\
prejudicar a segurança e o conforto \\
dos usuários; \\
-Evitar freadas bruscas; \\
-Evitar outras situações propícias a \\
acidentes.
\end{tabular}

-Manter velocidade compatível com o estado das vias, respeitados os limites legais;

-Não movimentar o veículo sem que estejam fechadas as portas;

-Respeitar os horários programados para a linha;

-Dirigir com cautela especial à noite e em dias de chuva ou de pouca visibilidade;

-Atender aos sinais de parada nos pontos estabelecidos.

- Comunicar a garagem quando ocorrerem indícios de defeito mecânico que possa pôr em risco a segurança dos usuários recolhendo o veículo quando autorizado.

-Respeitar as normas da empresa e as determinações da fiscalização.

\section{Variabilidade}

-Más condições das vias

-Tempo de viagem insuficiente em pelo menos uma das viagens previstas;

-Trânsito intenso.

-A OS nem sempre é atendida pelo setor de manutenção da empresa.

-Posto de trabalho inadequado (calor, ruído, assento inadequado); -Ambiente físico (terminal) precário, sem condições adequadas para a alimentação, higiene pessoal e repouso.

\section{Tarefa real}

-Conduzir o veículo sem poder evitar a trepidação e as freadas em consequência dos buracos, proporcionando aos passageiros algum desconforto. Há ainda o risco de envolver-se em acidentes ao desviar ou cair nos buracos.

-Dirigir com velocidade acima do limite, em alguns trechos, na tentativa de cumprir o tempo de viagem; -Dar partida no veículo com as portas ainda abertas na tentativa de cumprir ou compensar o tempo da viagem;

-Realizar a viagem sem cumprir os horários programados, em virtude da intensidade do trânsito, tendo como consequência a perda do intervalo entre as viagens, do horário de descanso ou ainda o aumento da jornada de trabalho;

-Realizar a viagem sem parar nas primeiras ou nas últimas paradas da linha (queima de parada) na tentativa de compensar o tempo da viagem.

-Dirigir o veículo que apresenta algum defeito mecânico, o que exige do motorista maior atenção esforço e pode colocar em risco a segurança dos usuários.

-Interrupção de viagem por mal-estar ou adoecimento;

-Jornada de trabalho não realizada por falta ao trabalho. 
Diante dos resultados que caracterizam a situação de trabalho do motorista, este estudo alcança seu objetivo geral ao apontar a existência de uma considerável distância entre o trabalho formalmente prescrito pela empresa e o trabalho real executado pelos motoristas. Esse distanciamento traz implicações para esse profissional como pessoa e para o resultado do seu trabalho, o que compromete o desempenho e a qualidade do serviço prestado pela empresa. Deve-se considerar, porém, que as ações para a redução ou a eliminação de algumas das variabilidades encontradas, como as más condições das vias e o trânsito intenso, não dependem de providências por parte da vontade da empresa, mas da decisão e da interferência do órgão gestor do transporte público.

Ao mesmo tempo em que revela os problemas da atividade do motorista, este estudo possibilitou relacionar a realidade encontrada e percebida pelos motoristas com as proposições dos subsistemas da administração de recursos humanos como forma de contribuir com a indicação para transformar essa atividade.

A referidas contribuições são relativas às políticas de recrutamento e seleção, avaliação de desempenho, atividades e programas compensatórios, política salarial e de benefícios, monitoração participativa e democrática e redução de fatores estressores no local de trabalho, visando a redimensionar a gestão da atividade do motorista.

A implementação de um modelo ou sistema de avaliação de desempenho, entre os vários disponibilizados na literatura, foi sugerido para levar a empresa a um melhor entendimento da situação de trabalho real do motorista, para que ele tome conhecimento de sua atuação e possa corrigir comportamentos e atitudes avaliados como inadequados, a fim de que a empresa identifique situações e fatores que constituam variabilidades e constrangimentos e possa atuar sobre elas. Assim, poderão ser identificados aspectos ocultos e reconhecidas as competências e os processos criativos dos motoristas ao lidar com as imprevisibilidades de sua atividade.

Ao considerar que os fatores subjetivos do trabalhador interferem em sua atividade, foi sugerido que sejam desenvolvidos programas e atividades que reforcem os fatores avaliados como satisfatórios pelos motoristas, como gostar de dirigir, o trabalho em si e os colegas de trabalho. Melhorias no ambiente de trabalho que proporcionem bem-estar e que melhorem a interação entre os colegas de trabalho, bem como ações que atribuam maior significado ao trabalho, deverão ter função compensatória, contribuindo para evitar a insatisfação no trabalho.

Tendo sido o salário avaliado como insatisfatório pelos motoristas, ao mesmo tempo em que se verificou que esse tem sido corrigido anualmente pelo índice oficial de reajuste, foi sugerido que a empresa utilize sua relação com os motoristas para comunicar-se melhor, para esclarecer sua política salarial. A empresa poderá ainda utilizar-se de outros componentes de recompensa, como elogios e acesso a programas de capacitação, bem como reavaliar os benefícios sociais que oferece, seja para medir seu valor, seja para flexibilizá-los.

Como a supervisão exercida sobre os motoristas foi avaliada predominantemente como insatisfatória, a empresa deverá preparar seus supervisores para exercer monitoração sobre os motoristas dentro de um estilo democrático e participativo, em detrimento de um sistema de controle rígido de fiscalização e de vigilância, de castigos e de penalidades, como tem sido feito. O sistema disciplinar sugerido deve ser baseado em regras construídas com a 
participação dos motoristas, e, após definidas, devem ser comunicadas a todos e atualizadas periodicamente; havendo comportamento inadequado, este deve ser avaliado pela observação e pela investigação, e, por fim, quando houver necessidade de aplicação do processo disciplinar, este deve ser realizado visando à mudança do comportamento, fornecendo-se suporte para tal mudança.

A empresa deverá ainda reduzir substancialmente os estressores no local de trabalho, como o barulho e o calor, a imprevisibilidade nas tarefas e a indefinição de linha e do horário em que o motorista irá trabalhar, oferecer um ambiente físico que propicie o desenvolvimento de atividades recreacionais e sociais durante as horas livres, oferecer recompensas tangíveis como bônus e folga, monitorar sinais de potenciais estresse para prevenir o estresse antes que se instale, cuidar para que as instalações de apoio sejam adequadas ao atendimento das necessidades fisiológicas e fornecer orientação sobre a importância de atividade física, alimentação balanceada e hábitos de vida prejudiciais à saúde, como o consumo exagerado da bebida e do cigarro.

Sendo essas proposições aplicadas pela empresa pesquisada, elas deverão aproximar o trabalho prescrito do trabalho real. Dessa forma, este trabalho traz uma contribuição prática para a organização, para o setor de transporte coletivo urbano e para o trabalhador, o motorista de ônibus, já que indica a necessidade da transformação efetiva do seu trabalho através da redução dos fatores que causam sofrimento e adoecimento.

As questões elucidadas neste estudo possibilitaram a interdisciplinaridade entre a Psicologia, a Administração de Recursos Humanos e a Engenharia de Produção; sem a intenção de encerrar o assunto, pelo contrário, essas questões ainda possibilitam o desenvolvimento de novas pesquisas sobre a gestão do serviço de transporte coletivo, o estado nutricional dos motoristas, a sua capacitação profissional formal e os aspectos psicodinâmicos dessa atividade. 


\section{Ladijane Sarmento da Silveira}

Graduada em Psicologia e Mestre em Engenharia de Produção pela Universidade Federal do Rio Grande do Norte, Natal - RN - Brasil.

E-mail: ladisarmento@hotmail.com

\section{Cynara Carvalho de Abreu}

Doutora pela Universidade Federal do Rio Grande do Norte e Professora do Departamento de Psicologia da Universidade Federal do Rio Grande do Norte, Natal - RN - Brasil.

E-mail: cynara.c.abreu@gmail.com

\section{Enilson Medeiros dos Santos}

Doutor pela Universidade Federal do Rio de Janeiro e Professor Associado IV do Departamento de Engenharia de Produção da Universidade Federal do Rio Grande do Norte, Natal - RN - Brasil.

E-mail: enilson@interjato.com.br

\section{Endereço para envio de correspondência:}

Alamedo dos Bosques, 680, Condomínio Bosque das Palmeiras, casa 160, Parque do Jiqui. CEP: 59153-155.

Parnamirim, RN. 


\section{Referências}

Abrahão, J. I. (2000, jun./abr.). Reestruturação produtiva e variabilidade do trabalho: uma abordagem da ergonomia. Psicologia: Teoria e Pesquisa, 16(1), 49 -54. doi: http://dx.doi. org/10.1590/S0102-37722000000100007

Associação Nacional das Empresas de Transportes Urbanos. (2008). Desempenho e qualidade nos sistemas de ônibus urbano. Brasília, DF.

Associação Nacional de Transportes Públicos. (2010, set./dez). Sobre desafios da mobilidade urbana para 2011. Revista dos Transportes Públicos, (33), 126.

Battiston M., Cruz, R. M., \& Hoffmann M. H. (2006). Condições de trabalho e saúde de motoristas de transporte coletivo urbano. Estudos de Psicologia (Natal), 11(3), 333-343. doi: http://dx.doi.org/10.1590/S1413-294X2006000300011

Bauer, M. W., \& Gaskell, G. (2002). Pesquisa qualitativa com texto, imagem e som. Petrópolis, RJ: Vozes.

Bendassolli, P. F., \& Soboll, L. A. (2011). Introdução às clínicas do trabalho: aportes teóricos, pressupostos e aplicações. In P. F. Bendassolli \& L. A. Soboll. (Orgs.), Clínicas do trabalho. São Paulo: Atlas.

Cadaval, M. (Coord.). (2001). Guia de marketing para o transporte coletivo (Vol. 1). Brasília, DF: NTU.

Chiavenato, I. (2008). Gestão de pessoas (3a ed.). Rio de Janeiro: Elsevier.

Falzon, P., \& Sauvagnac, C. (2007). Carga de trabalho e estresse. In P. Falzon (Org.), Ergonomia. (pp.141-154). São Paulo: Editora Blucher.

Ferreira, M. C. (2000). Atividade, categoria central na conceituação de trabalho em ergonomia. Revista Alethéia, 1(11), 71-82.

Gil, A. C. (1996). Métodos e técnicas de pesquisa social (4a ed.). São Paulo: Atlas.

Guérin. F., Laville, A., Danielou, A., Durafourg, J. , \& Kerguelen, A. (2001). Compreender o trabalho para transformá-lo: a prática da ergonomia. São Paulo: Edgar Blücher.

Gonçalves, E. C. (2003). Constrangimentos no posto do motorista de ônibus urbano segundo a visão macroergonômica. Dissertação de mestrado em Engenharia. Universidade Federal do Rio Grande do Sul, Porto Alegre, RS.

Lacombe, F. J. M. (2005). Recursos humanos: princípios e tendências. São Paulo: Saraiva.

Lima, M. E. A. (2011). Abordagens clínicas e saúde mental no Brasil. In P. F. Bendassolli \& L. A. Soboll, (Orgs.), Clínicas do trabalho. (pp. 227-257). São Paulo: Atlas.

Limongi-França, A. C. (2009). Práticas de recursos humanos. São Paulo: Atlas.

Mendes, A. M. (Org.). (2007). Psicodinâmica do trabalho: teoria, método e pesquisas. São Paulo: Casa do Psicólogo.

Milkovich, G. T., \& Boudreau, J. W. (2000). Administração de recursos humanos. São Paulo: Atlas.

Muchinsky, P. M. (2004). Psicologia organizacional. São Paulo: Pioneira Thomson Learning.

Oliveira, M. M. (2007). Como fazer pesquisa qualitativa. Petrópolis, RJ: Vozes.
Ribeiro, A. de L. (2006). Gestão de pessoas. São Paulo: Saraiva.

Rossi, A. M., Quick, J. C., \& Perrewe, P. L. (2009). Stress e qualidade de vida no trabalho: o positivo e o negativo. São Paulo: Atlas.

Rodrigues, M. A., \& Sorrattini, J. A. A qualidade no transporte coletivo urbano. Recuperado em 27 de maio de 2012 de http://d.yimg.com/kq/groups/1624466/543475367/name/A+ qualidade + no + transporte + coletivo + urbano.pdf.

Santos Júnior, E. A. (2003). De que adoecem e morrem os motoristas de ônibus. Revista Brasileira de Medicina do Trabalho, 1(2), 138-147.

Secretaria Regional do Trabalho do Rio Grande do Norte. (2011). Convenções coletivas. Recuperado em 27 de abril de 2011 de http://www.mte.gov.br/mediador.

Silva, C. O., Barros, M. E. B., \& Louzada, A. P. F. (2011) Clínica da atividade: dos conceitos às apropriações no Brasil. In P. F. Bendassolli \& L. A. Soboll (Orgs.), Clínicas do trabalho. São Paulo: Atlas

Trierweiller, A. C., Azevedo, B. M., Pereira V. L. D. V., Figueiredo Junior R., Moraes, R., Gontijo L. A. (2007). A estratégia operatória utilizada pelos trabalhadores e o hiato existente entre o trabalho prescrito e o trabalho real. In Anais do 27 Encontro Nacional de Engenharia de Produção. Foz do Iguaçu, PR.

Spector, P. E. (2002). Psicologia nas organizações. São Paulo: Saraiva.

Vidal, M. C. (2008). Guia para análise ergonômica do trabalho (AET) na empresa. Rio de Janeiro: Virtual Científica.

Wisner, A. (1987). Por dentro do trabalho: ergonomia: método e técnica. São Paulo: FTD. 